\title{
Narrativas entrelaçadas no ensino superior - Como nos constituímos enquanto comunidade e produzimos colaborativamente conhecimento emancipatório sobre investigação baseada em artes?
}

\footnotetext{
(iD) Ana Serra Rocha ${ }^{1}$, (iD) Ana Paula Caetano ${ }^{2}$, iD Ana Luisa Paz ${ }^{3}$

1, 2, 3 Universidade de Lisboa. Instituto de Educação, UIDEF. ${ }^{1}$ Universidade de Lisboa, ${ }^{1}$ Faculdade de Belas Artes, CIEBA.

1 Universidade do Porto, Faculdade de Belas Artes, Faculdade de Psicologia e de Ciências da Educação.

Autor para correspondência/Author for correspondence: rocha.ana@campus.ul.pt
}

RESUMO. Este artigo configura uma narrativa colaborativa de três elementos do Grupo de Estudos em Processos Participativos e Artísticos em Investigação e Educação (GEPPAIE), composto por investigadores em formação (docentes, doutorandos e mestrandos em áreas da Educação). Parte da interrogação: como temos vivido, enquanto grupo de estudos do ensino superior, nossos espaços de encontro(s) para a produção de conhecimento emancipatório sobre a investigação, nomeadamente sobre a pesquisa baseada em artes? Esta interrogação desdobra-se noutras e é mote para apresentarmos o já produzido coletivamente, mas também para criarmos as novas escritas e reflexões que estão vertidas neste texto. Integra-se, ainda, no doutoramento de Ana Serra Rocha, centrado na problematização de A experiência do lugar do livro como um lugar de reflexão epistemológica na educação artística, visando ampliar a reflexão sobre o campo da educação artística e sobre os estudos doutorais desenvolvidos nesta área. Tem por objetivo refletir sobre os processos participativos de criação colaborativa e sobre algumas questões que se têm vindo a debater no GEPPAIE, nomeadamente de ordem relacional e metodológica, tendo em vista a (des/re)construção do conhecimento e a problematização das suas formas de organização escrita e visual.

Palavras-chave: comunidade relacional, construção dialógica de conhecimento, narrativas colaborativas, cardografia, tese de doutoramento. 


\title{
Intertwined narratives in higher education - How do we constitute ourselves as a community and collaboratively produce emancipatory knowledge about arts-based research?
}

\begin{abstract}
This article sets up a collaborative narrative of three elements from the Group Study on Participatory and Artistic Processes in Research and Education (GEPPAIE), composed of researchers in academic and professional development (professors, doctoral and master's students in Education areas). It begins with a question: how have we experienced, as a higher education study group, our meeting spaces for the production of emancipatory knowledge about research, especially about arts-based research? This question unfolds into others and drives us to what has already been produced collectively, but also boosts the new writings and reflections in this text. It is also part of Ana Serra Rocha's PhD, focused on the problematization of The book's experience as a place of epistemological reflection in artistic education, aiming at a broader reflection in the field of artistic education and in doctoral studies. It speculates on the participatory processes of collaborative creation and on some issues that have been debated at GEPPAIE, namely of a relational and methodological nature, with a view to (des/re)construction of knowledge and its forms of written and visual representation.
\end{abstract}

Keywords: relational community, dialogic knowledge construction, collaborative narratives, cardography, doctoral thesis. 


\section{Narrativas entrelazadas en la educación superior: ¿cómo nos constituimos como comunidad y producimos en colaboración conocimiento emancipatorio sobre la investigación basada en las artes?}

RESUMEN. Este artículo configura una narrativa colaborativa de tres elementos del Grupo de Estudios en Procesos Artísticos y Participativos en Investigación y Educación (GEPPAIE), integrado por investigadores en formación (profesores, estudiantes de doctorado y máster en áreas de Educación). Comienza con una pregunta: ¿cómo hemos vivido nosotros, como grupo de estudio de educación superior, nuestros espacios de encuentro para la producción de conocimiento emancipatorio sobre la investigación, es decir, sobre la investigación basada en las artes? Esta pregunta se desdobla en otras y es el lema para presentar lo ya producido colectivamente, pero también para crear los nuevos escritos y reflexiones que se reflejan en este texto. También forma parte del doctorado de Ana Serra Rocha, centrado en la problematización de El lugar de la experiencia del libro como lugar de reflexión epistemológica, en el contexto de la educación artística, con el objetivo de ampliar la reflexión sobre el campo de la educación artística y sobre los estudios de doctorado desarrollados en este ámbito. Tiene como objetivo reflexionar sobre los procesos participativos de creación colaborativa y sobre algunos temas que se han debatido en GEPPAIE, es decir, de carácter relacional y metodológico, con miras a la (des/re) construcción del conocimiento y la problematización de sus formas de escritura y organización visual.

Palabras clave: comunidad relacional, construcción dialógica del conocimiento, narrativas colaborativas, cardografía, tesis de doctorado. 


\section{Introdução}

\begin{abstract}
Obrigada GEPPAIE, pela oportunidade de "uma narrativa dinâmica com enredo fluido, costurado com fragmentos das múltiplas histórias que vivenciamos $e$ compartilhamos de diversas formas com alguns mais próximos física e digitalmente" (Moran, 2015, p. 31). C.S. Correia, comunicação pessoal por email, abril, 2020).
\end{abstract}

Este artigo trouxe-nos a possibilidade de regressar ao passado, mais e menos longínquo, para fazer a genealogia do Grupo de Estudos em Processos Participativos e Artísticos em Investigação e Educação (GEPPAIE), na perspectiva de relançar os passos a seguir. Muitas são as questões que emergem e se mantêm em aberto: quais os propósitos e a identidade de cada um no grupo? Quem somos? O que queremos? O que cada um é no coletivo? O que é o coletivo para cada um de nós? Somos um grupo - seremos uma comunidade? O que nos emancipa como investigadores? Temos um centro ou somos rizoma, sem centro nem periferia, sem dentro nem fora? Quando entrámos? Suspendendo-nos temporariamente, manter-nos-emos dentro? Em movimento... A que compromissos nos dispomos?

Queremos produzir juntos: projetos, artigos, livros, comunicações, eventos. Queremos ter lugar enquanto indivíduos com projetos próprios. Para cada um, o grupo representa-se como espaço de liberdade que nos constrange a refletir, que nos desafia a re-equacionar o nosso lugar neste mundo.

Ao mesmo tempo, este artigo pretende ser parte integrante da Tese de Doutoramento em Educação Artística da primeira autora, que se propõe, a partir de uma metodologia baseada em artes (artsbased research), investigar $A$ experiência do lugar do livro como um lugar de reflexão epistemológica na educação artística, centrada em processos participativos que ocorrem no ensino superior e que se desenvolvem utilizando dispositivos artísticos, nomeadamente em workshops organizados em torno de uma pergunta de investigação.

Ana Serra Rocha tem mantido uma forte convicção na importância de apresentar publicamente o(s) processo(s) e resultado(s) da investigação; através de metodologias baseadas em artes, como a a/r/tografia, assentes numa dimensão artística, que entrelaça a construção de objetos de investigação, texto e imagem gráfica, num diálogo entre os processos pedagógicos e a construção de conhecimento.

A partir dos encontros e da investigação realizada no GEPPAIE, a 
autora desenvolveu o novo conceito de cardografia, inspirada na sequência de registos realizados durante a primeira sessão do grupo, em pequenos cartões de $10 \mathrm{~cm} \times 10 \mathrm{~cm}$. A adaptabilidade destes cartões modelares permite que funcionem como repositórios (inter)subjetivos dos acontecimentos vividos pelos participantes e re-significados na criação dos registos, levando a que, no seu conjunto, se constituam como novos objetos de investigação.

Tal como na $a / r /$ tography, em que as três primeiras letras introduzem um significado, com A - artist (artista), R researcher (investigador), $\mathrm{T}-$ teacher (professor), na cardography, as quatro primeiras letras representam: card (cartão, como folha ou parte de um livro) e as restantes graphy (como a escrita ou grafia em que nele é impressa). Cada letra individualmente é entendida como: C context (contexto), A - artistic (artístico), $\mathrm{R}$ - research (re-significação), e D - doing (acção de fazer). Estes cartões modelares assumem-se como registo, num contexto específico, que parte de uma pergunta de investigação, e se desenvolve através de uma metodologia baseada em artes, envolvendo as tessituras dos participantes no registo cardográfico, tendo em vista a criação e a partilha visual da pesquisa através da construção de uma investigação.
O artigo convoca estes e outros processos de construção de conhecimento que têm vindo a ser ensaiados no GEPPAIE, interroga a sua dimensão colaborativa e a inserção numa tese de doutoramento. No caso de uma tese formada por artigos, como é o caso do processo levado a efeito por Ana Serra Rocha, a situação leva-nos a assumir que o artigo é mais uma página, composta de fragmentos de outras, um hipertexto que tece a história que vamos construindo do nosso mundo-comunidade, mas também página de outros livros que se têm vindo a construir sobre processos participativos e artísticos de investigação e formação.

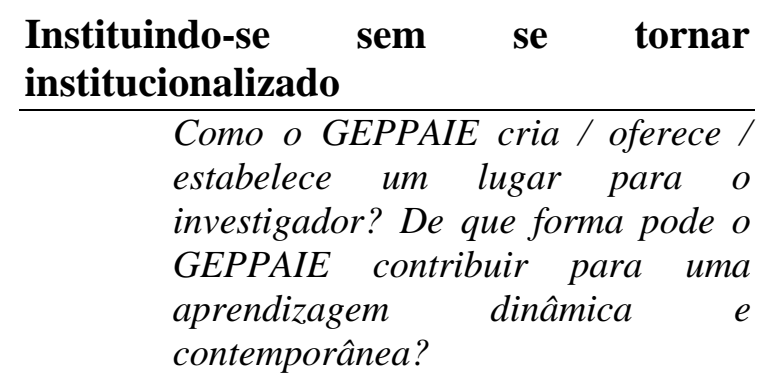

O Grupo de Estudos em Processos Participativos e Artísticos de Investigação e Educação (GEPPAIE) foi originalmente proposto por Ana Paula Caetano e Ana Luísa Paz (professoras do Instituto de Educação da Universidade de Lisboa), constituindo uma comunidade de aprendizagem, composta por elementos do corpo docente, investigadores, e estudantes. Somos um grupo informal de 
investigadores, doutorandos e mestrandos das áreas da educação e formação, nomeadamente de Educação Artística, Formação de Professores, Formação de Adultos e Desenvolvimento Social e Cultural, maioritariamente do Instituto de Educação da Universidade de Lisboa e do seu Centro de Investigação - a Unidade de Investigação e Desenvolvimento em Educação e Formação (UIDEF). Uma vez que o Doutoramento em Educação Artística é um programa conjunto entre a Universidade de Lisboa - através da sua Faculdade de Belas Artes e Instituto de Educação - e a Universidade do Porto através das suas Faculdades de Belas Artes e de Psicologia e de Ciências da Educação - há também membros apenas inscritos no Centro de Investigação da Faculdade de Belas Artes da Universidade de Lisboa (CIEBA).

A criação deste grupo de trabalho decorre de pesquisas colaborativas anteriores entre docentes e discentes centradas nesses temas, dos quais se destacam, como mais recentes e envolvendo alguns dos autores deste artigo, as publicações de Caetano et al. (2019a, 2019b, 2020a, 2020b), Machado et al. (2020), Paz e Caetano (2019, 2020).

O grupo de estudos pretende aprofundar a pesquisa e reflexão sobre processos participativos e/ou artísticos de investigação e educação; garantir um espaço de encontro, investigação e reflexão onde se cruzam processos de leitura e de escrita coletiva em temas de interesse comum para os participantes que desenvolvem pesquisas mobilizando metodologias participativas e artísticas; refletir e aprofundar coletivamente problemáticas socias e de interesse para os participantes; explorar metodologias baseadas em artes com contributo para a comunidade educativa em geral.

No início, em 2020, o convite foi lançado a professores e estudantes por email, e na primeira sessão a 5 de março foi apresentada a proposta referente ao GEPPAIE. A sessão presencial iniciou-se com 14 elementos e foi lançado o desafio de efetuar um registo gráfico individual durante o decurso da sessão, através de cartões de $10 \mathrm{~cm}$ x $10 \mathrm{~cm}$, o que no final resultou numa construção cardográfica testemunhando a história colectiva (imagem 1). 
Imagem 1 - GEPPAIE, $1^{\text {a }}$ Cardografia - construção colaborativa resultante das grafias individuais durante a sessão de 5 março 2020 utilizando cartões de $10 \mathrm{~cm} \mathrm{x} \mathrm{10cm.}$

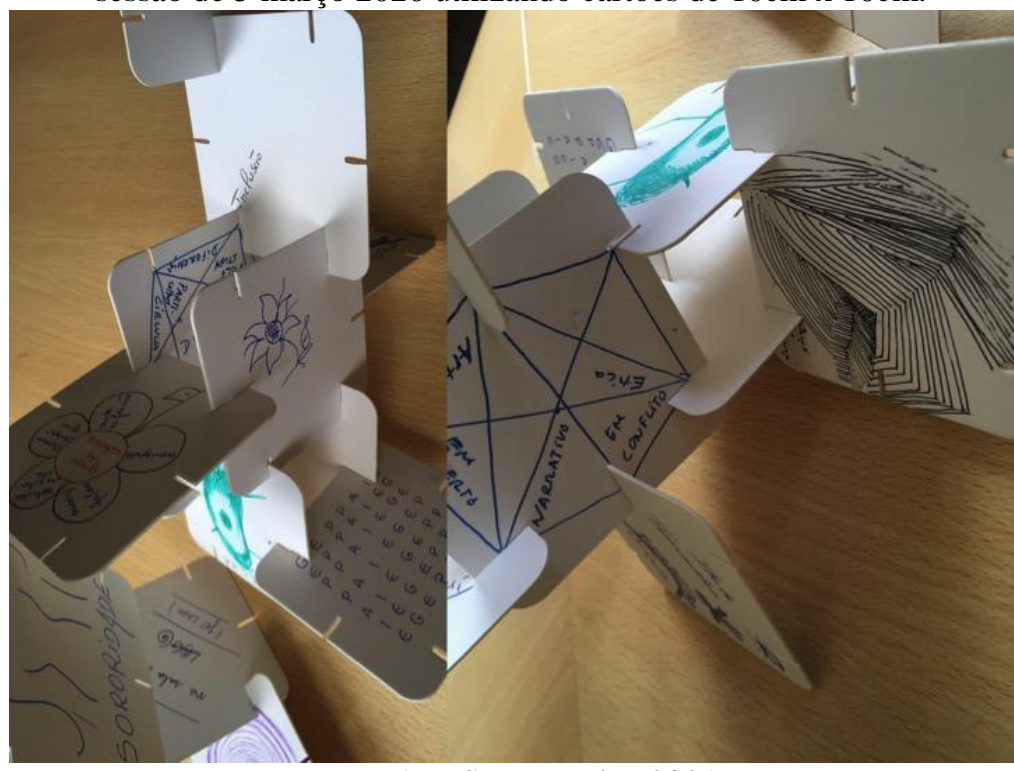

Fonte: Ana Serra Rocha, 2021.

Durante a pandemia iniciámos o processo de encontros à distância por videoconferência, o que aproximou participantes do grupo que, de outro modo, não poderiam estar presentes pela localização geográfica dispersa. O querer manter essa possibilidade e a dificuldade de um processo de comunicação com um grupo misto, com alguns presentes de corpo e máscara e outros tentando acompanhar do outro lado do ecrã, levounos a manter o processo de encontros remotos e síncronos.

Neste momento, em setembro de 2021, contamos com 34 membros, embora haja um núcleo mais persistente e ativo de cerca de 12 mulheres (Rocha, Paz, Caetano, S. Gomes, Ré, Augusto, Teixeira, Correia Silva, G. Nascimento, Martins,
Paixão e Silva, Marques), mantendo-se os restantes mais ausentes por indisponibilidades várias, entre as quais os afazeres profissionais, mas manifestando interesse em continuar a acompanhar os trabalhos. Alguns membros nesta situação aparecem pontualmente nas reuniões, como Bartasevicius, Bila, D. Nascimento, D. Gomes, Sarmento, Almeida Gomes, Lacerda, entre outros.

Atualmente, reunimos em sessões quinzenais e, normalmente, no início da sessão é apresentado o objectivo (aliás muitas vezes definido na sessão anterior), para, durante os 15 dias de intervalo, ser partilhado o que se irá apresentar/debater na sessão seguinte, normalmente com o suporte de um texto para uma leitura prévia. Entre sessões, vão-se 
disponibilizando, nas plataformas digitais do grupo, artigos, documentários, vídeos e outros elementos que constituem espaços e encontros de partilha, provocação e aprendizagem, numa base em que os projetos de trabalho emergem coletivamente a partir dos interesses de todos, atuando simultaneamente com o pensar-sentir-fazer-refletir-partilhar, perspectivando diferentes processos participativos e artísticos de investigação e educação.

No final de cada sessão é redigida uma ata, uma cardografia ou outro suporte visual, que é disponibilizado na google drive. Pretendemos promover a construção colectiva de conhecimento, baseado no diálogo igualitário, na reflexão e manufatura de objetos (escrita ou grafia), e no desenvolvimento de um repositório (digital) de produções escritas e visuais correlacionadas com as inquietações levantadas pelo grupo, entre as quais destacamos algumas questões que nos têm inquietado:

- O que é a investigação participativa?

- Que questões éticas se colocam na investigação participativa e nas nossas investigações em particular?

- Que tensões e dilemas temos vivido no decorrer das nossas investigações participativas e baseadas em artes?
- Como me construo enquanto investigador?

- Como as nossas investigações são também formadoras de e para os seus diversos participantes?

- Qual o lugar possível para uma participação colaborativa na escrita de uma tese de doutoramento?

Para além de livros e artigos dos autores que se ocupam destes temas e que têm alimentado a nossa pesquisa e reflexão, temos vindo a compilar textos nossos que vão sendo produzidos ao longo do tempo, alguns de modo individual e outros coletivamente, e que são disponibilizados entre as sessões quinzenais, pelo que utilizamos frequentemente o google drive, ferramenta que nos permite escrever colaborativamente estando os seus membros sediados em diferentes pontos do globo (entre Portugal, Brasil e Alemanha), sincrónica e assincronicamente. São disso exemplo:

- Escritas coletivas em construção: Quarentena em 100 atos: Mea Culpa/Culpa Minha; reflexões síncronas em suporte digital no google drive, padlet e canvas.

- Sínteses colaborativas das reuniões: atas e cardografias coletivas.

- Escritas individuais em construção: fanzines, diários, cardografias, excertos de projetos de investigação e de teses de 
doutoramento.

- Repositório relacional: partilha de textos para reflexão, de autores diversos.

- Comunicações em congressos, seminários, encontros.

Ao longo deste ano e meio de trabalho conjunto temos vindo a ensaiar caminhos, tendo o primeiro ano, entre março e setembro de 2020, sido pautado por aprofundar conceitos, concepções e problemáticas relativas à investigação participativa, e o segundo ano (de setembro de 2021 até à presente data) tem sido diversificado, uma vez que nos centrámos mais (embora não apenas) em questões metodológicas das teses de doutoramento, nomeadamente sobre processos de pesquisa baseada em artes, cartografias, narrativas visuais, diários, processos de (auto)formação apoiados em tecnologias digitais, entre outros.

\section{O lugar de encontro(s) numa comunidade relacional}

Como a comunidade é
simultaneamente um lugar de
reconhecimento mútuo e de
construção coletiva? Que
complexidades e ambiguidades
experimentamos em relação a
comprometimentos com o grupo e
com sentidos de pertença?

O GEPPAIE é um grupo que se forma organicamente, autorizando e convidando a entrada de elementos ao grupo em qualquer sessão, promovendo o espaço de encontro no âmbito dos processos e práticas de investigação. Foram notórias as mudanças na composição dos membros ativos no grupo, o que fará dele uma possibilidade em aberto, sem obrigatoriedade de frequência, flexível quanto aos modos de participação, acomodando e não excluindo aqueles que querem permanecer e acompanhar os trabalhos de forma mais indireta, mesmo que não consigam acompanhar todas as sessões.

Esta opção assenta em princípios de inclusão e de uma prática pedagógica pautada por relações paritárias, diálogos igualitários e horizontais (Flecha, 2015) que procura proporcionar eventos de aprendizagem e de suporte a aprendizagens reais (Atkinson, 2015, 2018). Desencadeando eventos de grafia e de escrita, encontros inesperados/improváveis num suporte digital através de uma escrita coletiva iniciada no ano letivo 2019/2020 e ainda em curso, entrelaçam-se experiências e saberes de investigadores.

Questionamo-nos com frequência sobre os diferentes papéis no grupo, cada elemento revelando as suas características de acordo com as possibilidades e interesses, ou mesmo áreas a descobrir. Existe uma rotatividade nos papéis 
representados, sendo estes mutáveis durante a mesma sessão ou entre sessões, podendo cada elemento assumir o seu papel de acordo com a intenção e necessidade. Esta cultura colaborativa e flexível revela-se ainda no predomínio de interações por acomodação (combinação e fusão), mais do que por oposição e conflito (Maisonneuve, 2004). As tomadas de decisão do grupo revelam a dimensão sócio-afetivo entre elementos do grupo tecendo teias estabelecidas por relações de investigações e outras de pertenças. É claro o entrelaçamento existente, vai acontecendo num processo de reciprocidade, no sentido da capacidade de escuta, compreensão e adaptação de participação ao grupo.

Assim, as sessões de balanço acontecem com abertura e busca de autenticidade em reflexões síncronas, a partir de um questionamento e desenvolvendo metodologias tomadas como participativas através de plataformas digitais. Mobilizamos depoimentos vários em momentos de balanço, testemunhos dialógicos acerca da relevância do grupo e dos seus processos para cada um, mais uma vez tomando formas diversas, como é o caso de cardografias individuais, de artografias colaborativas integradas em padlets e de excertos de diálogos que foram acontecendo e se foram anotando em diários, que são constituintes deste corpo de texto. É disso exemplo a sessão de 19 de março de 2019 (imagem 2), onde estiveram on-line 11 participantes dedicados a refletir sobre quatro eixos: o que tem sido o GEPPAIE, o que gostaria que fosse, o que poderá vir a ser, que transformação?

Imagem 2 - GEPPAIE, Padlet colaborativo durante a sessão de balanço GEPPAIE (2019 - em curso) e QR code.

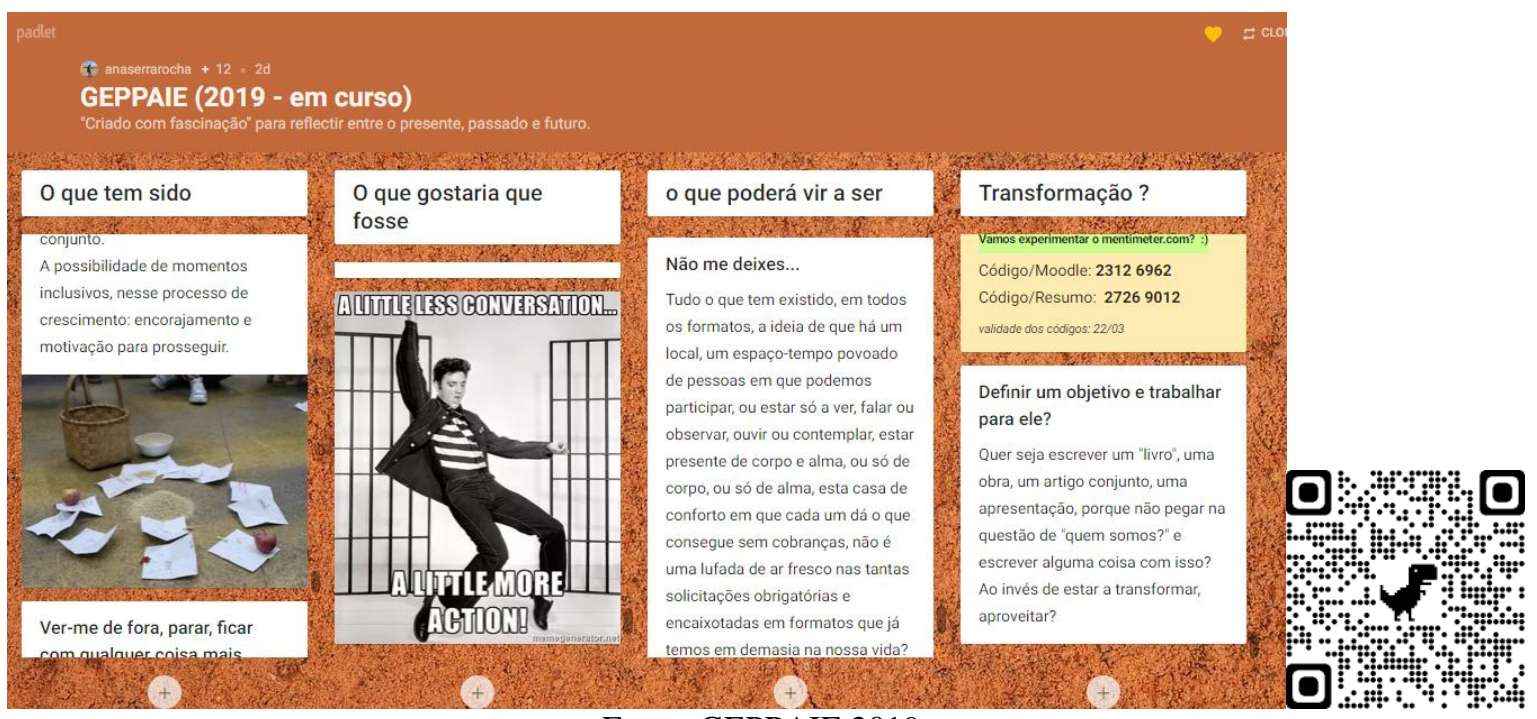

Fonte: GEPPAIE 2019. 
De acordo com as conclusões deste último balanço, o grupo pretende continuar a insistir numa educação não-formal, recusando por agora a hipótese de institucionalização, promovendo o diálogo como fonte primeira de construção de conhecimentos.

A trama enraizada do processo colaborativo estabelece uma sinergia ativa atenta às imprevisibilidades do momento(s), articulada de forma flexível e organizada de forma variável. Esta dinâmica parece espelhar o diagrama C desenvolvido por Paul Baran nos anos 60 . De acordo com a imagem 3, os diagramas A e B apresentam um modelo centralizado e hierárquico, convergente num ponto (ou mais), interrompendo o fluxo de comunicação, podendo ser centralizada num só nódulo ou em vários. O diagrama C, apresenta uma total conexão entre os 'nódulos', em que os elementos do grupo estão distribuídos em rede.

Imagem 3 - Diagrama de Paul Baran.

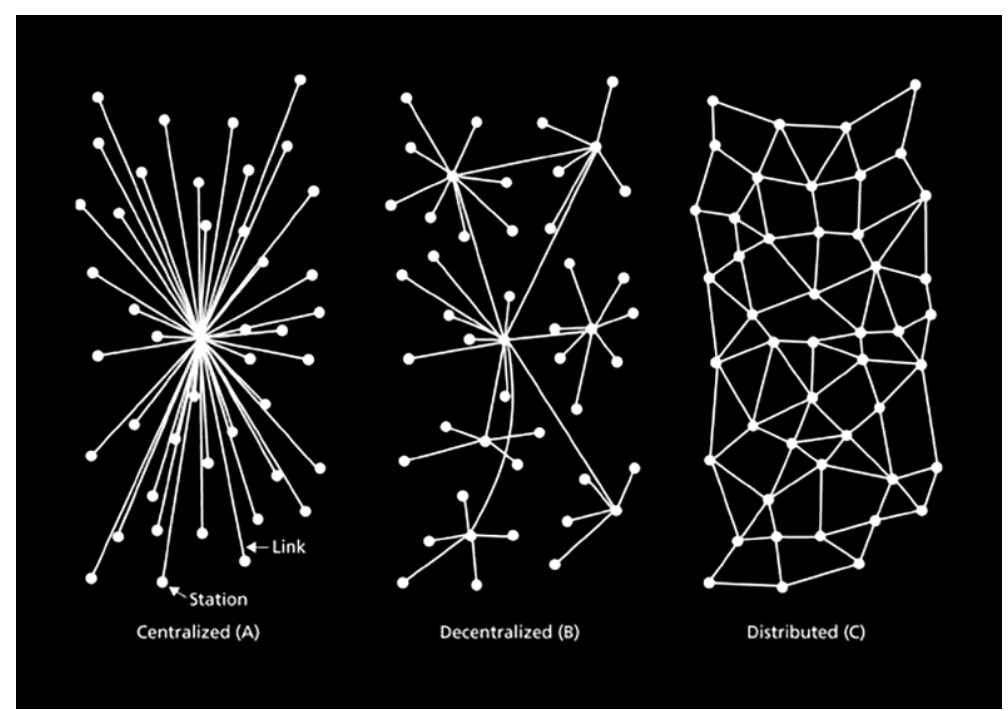

Fonte: (Baran, 1964, p. 2).

No entanto, por vezes acontecem momentos durante as sessões que estão de acordo com o esquema do diagrama B, quando surgem micro-propósitos combinados entre elementos do grupo, ou com o esquema $\mathrm{A}$, em que um dos elementos centraliza uma dinâmica para o restante grupo. Esta rede existe em pleno funcionamento, porque é viva, e a sua morfologia configura-se intrinsecamente de acordo com as necessidades grupais. A investigação colaborativa apresenta-se baseada na confiança, no diálogo e na comunicação autêntica com diferentes 
formas e ritmos de colaboração. "A colaboração não é um fim em si mesma, mas sim um meio para atingir certos objetivos. Por isso, objetivos diferentes, procedem em condições bastantes diversas, exigem naturalmente, formas de colaboração também muito diversas" (Boavida \& Ponte, 2002, p. 3). De facto, "quanto mais diversificada for a equipa maior esforço e mais tempo são necessários para que funcione com êxito, dada a variedade de linguagens, quadros de referência e estilos" (p. 5). Esta colaboração heterogénea e espontânea possibilita que o grupo se redefina como grupo em todas as sessões, pois nem sempre estão os mesmos elementos. Já Deleuze e Guattari (2002) propõem, com o mesmo sentido, pensar o grupo como um movimento subjetivo orgânico e maleável, ou seja, dinâmico, interagindo na horizontalidade, verticalidade e na profundidade dos eixos de entendimento grupal; assumindo uma transversalidade atuante na troca de papéis por cada membro do grupo. Esta colaboração relacional tece a sua trama, (des)construindo interesses e partilhas, face aos sentimentos de segurança e de pertença existentes, onde "o sentimento de comunidade dilui e previne os sentimentos de isolamento, solidão e alienação dos indivíduos das suas comunidades" (Ornelas, 2008, p. 39).

\section{Dinâmicas dialógicas em torno dos projectos de investigação}

Como os processos colaborativos são aprofundados pela integração de dimensões artísticas? De que forma a cardografia acompanha as necessidades da investigação?

Nas dinâmicas dialógicas, a exploração de um tema, questão ou outra sugestão trazida ao grupo, tem sido uma preocupação constante.

Esta partilha revela as necessidades dos participantes ao longo do desenvolvimento da escrita dos seus artigos científicos, projetos, candidaturas a programas específicos, participação em congressos ou seminários, entre outras situações. O grupo opera como um laboratório coletivo de experimentação e cogestão participativa. Fomentam-se diálogos e conversas por imagens, escritas, sons e silêncios, elementos de uma educação livre no sentido de Paulo Freire (1975, 1977), valorizando também a aprendizagem experiencial, cultural e emocional. O grupo faz acontecer um encontro de educação libertadora, emancipatória, no diálogo, cooperação, união, partilha e aquisição de conhecimento. Este diálogo igualitário, corresponde ao reconhecimento de cada sujeito, e promove a transformação na 
construção de sentidos e aplicabilidade aos projetos em curso, de acordo com Loss (2019)

necessitamos de vivenciar e fazer experiências nos espaços educativos com propostas de autoformação. A autoformação e a construção de sentido aos nossos sentidos, é a busca do significado de quem somos e para onde queremos ir. ... Ainda, a autoformação possibilita ao ser humano a reflexão de si mesmo, na dinâmica da auto-observação, para o alargamento das capacidades de autonomização, de iniciativa e criatividade. (p. 70).

Ao contrário do ano de 2019/20, onde nos centrámos na clarificação de conceitos e problematização de questões amplas sobre processos participativos de investigação, no ano de 2020/21 assumimos que uma parte substancial das sessões seria desenvolvida em torno dos projetos de investigação individuais, nomeadamente nas teses de doutoramento que se estão a desenvolver. Ainda assim, procurámos empreender processos de pesquisa teórica, reflexão e criação dialógica que extravasassem o interesse individual. Consideramos que os processos colaborativos através da escrita e da prática, ajudam os estudantes a realizarem progressos e a suportar a teia rizomática de, e para, a investigação, estabelecendo uma construção de confiança e horizontalidade, ritmada por um vai-e-vem entre trabalho conceptual mais abstrato e reflexão sobre os projetos concretos, com e em constante feedback integrado no próprio processo.

A título de exemplo, na sessão dinamizada a 5 de fevereiro do corrente ano, uma das investigadoras do grupo, propôs a reflexão sobre o tema da sua tese de doutoramento, em torno do seguinte desafio:

o que me move, a partir das características de vivência do tempo contidas nos conceitos clássicos de kairos (momento oportuno) e otium (na sua concepção grega: tempo para o estudo), que têm na sua base a experimentação de um tempo qualitativo. Pretende-se perceber de que forma é que estes conceitos têm evoluído e que espaço ocupam no nosso quotidiano, particularmente no que respeita à educação e aos processos de criação artística teatral. (Augusto, 2021, p. 1).

Assim, ao longo da sessão, enquanto acompanha a discussão kairótica, Ana Serra Rocha desenvolve a sua cardografia em duas folhas A4 (imagem 4), iniciando com os cartões modelares para delinear a superfície horizontal na criação de espaços temáticos. A cardografia apresenta espaços que são ocupados pelas temáticas abordadas: sistema de ensino, objecto tese, construção do espaço branco, processos de criação artística, entre outros. Existe um desenvolvimento gráfico aliado aos elementos de escrita, que acompanham o observador na rotação do olhar e da 
manipulação da superfície, para alcançar a

espacial.

leitura de acordo com a orientação

Imagem 4 - GEPPAIE, Cardografia realizada por Ana Serra Rocha durante a sessão de 5/2/2021 centrada numa investigação-tese doutoramento. Formato A4.

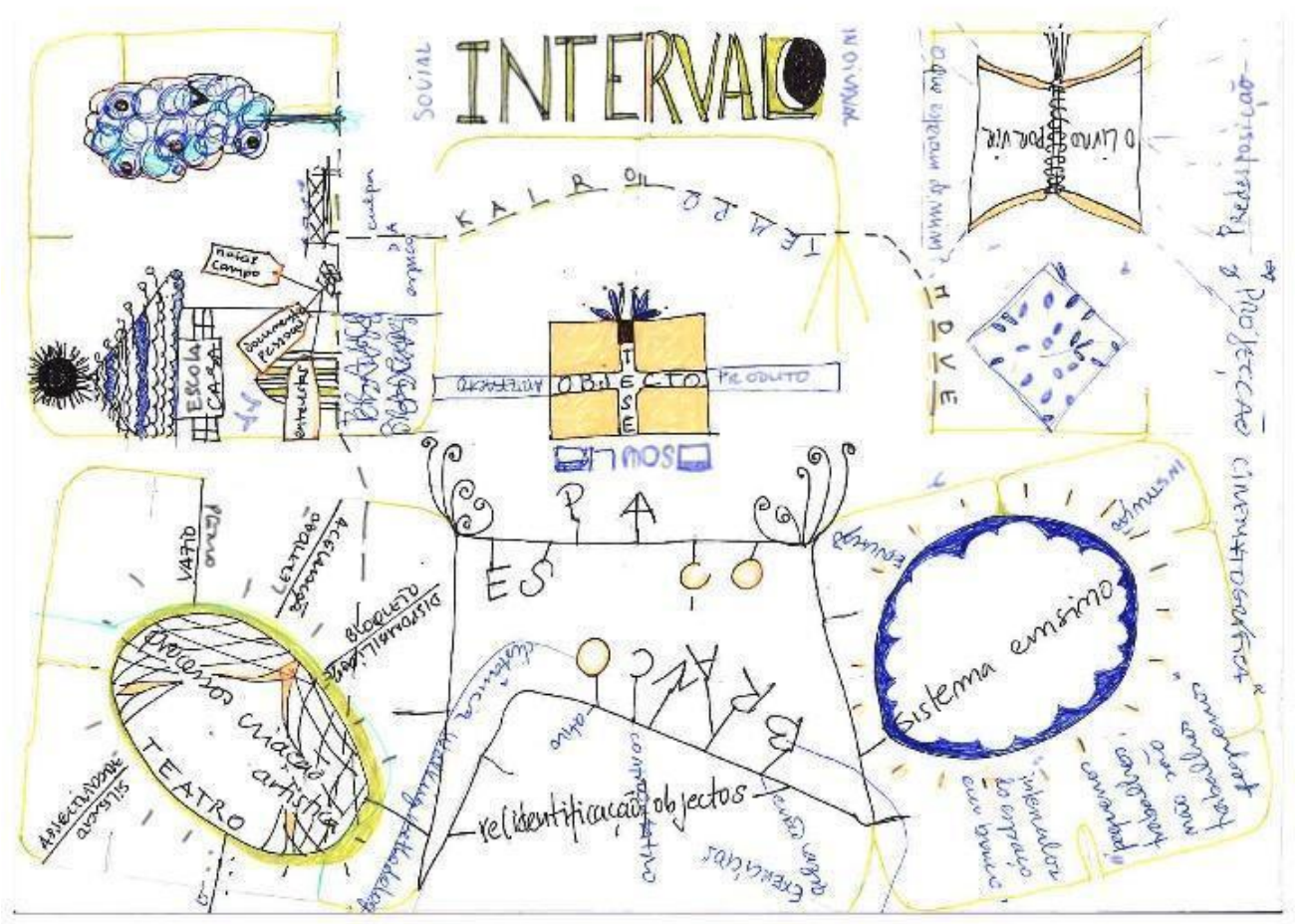

Fonte: Ana Serra Rocha 2021.

Para além destas incursões por projetos individuais, várias outras iniciativas dialógicas acontecem a partir de diversos membros do GEPPAIE, através de interligações de propostas de investigações. Playing Scenes é um workshop criado e desenvolvido por Ana Serra Rocha e Ana Rita Teixeira, apresentando-se como uma

proposta entendida como uma oportunidade de explorar um encontro entre dois projetos de pesquisa de doutoramento em educação artística, que desejam explorar a pesquisa visual através do movimento, desenho e escrita. ... Criado como um workshop online (fevereiro 2020), explorado por 6 investigadores (3 do GEPPAIE) de diferentes áreas de ensino, desenvolvido em torno da questão: como podemos co-criar uma cardografia espacial do processo de reprodução da construção de significados em workshops de experiências, combinando a ideia de corpos e livros como locais de aprendizagem?

O projeto do workshop é criado a partir de um novo conceito da artografia, denominado cardografia, (inventado por um dos autores para endossar uma metodologia baseada em um cartão) como um evento para: aprender sobre uma metodologia de pesquisa baseada nas artes; envolver uma experiência rizomática de compartilhamento de (re)significações por meio de corpos e processos de movimento de livros; emaranhar conexões entre o estado de abertura 
ao conhecimento e a (re) significação do propósito de pesquisa criativa de cada um. (Teixeira \& Rocha, 2021, no prelo).

Este caminho revela-se como uma forma de tornar visível a investigação, abrindo espaço para um ensaio narrativo visual do processo de recriação intersubjetiva de significados onde "os modos singulares de cada (participante) se expressam e juntos definem linhas comuns de ação" (Pina \& Caetano, 2019, p. 112). Criam-se, assim, propostas orientadas pela noção de imanência da aprendizagem, de Atkinson (2012), deixando que as (co) vivências nos afetem com entendimentos de (des)apego, bem como novas formas de contato-improvisação, para (des)enrolar os encontros de nossos projetos de pesquisa.

\section{Processos coletivos de criação}

Como podem os processos colaborativos ser aprofundados pela dimensão visual e artística de uma metodologia baseada em artes? Que possibilidades se abrem com a exploração das potencialidades das ferramentas digitais na construção do livro?

Construímos ambientes informais de convívio e de aprendizagem em contexto universitário refletindo sobre processos de investigação, disponibilizando textos e escritas no google drive com livre acesso para todos, o que possibilita a utilização deste espaço de repositório relacional como um diálogo interativo.

No grupo, o autor é um coletivo e as narrativas visuais e escritas convivem entre si, de forma artística ou em escrita narrativa; habitamos este espaço interceptando o tema do encontro e as histórias pessoais, como elementos de experiências colaborativas na construção conjunta de significado. Este portfólio constitui-se como um caderno digital, ponto de encontro e zona de estar dos elementos do grupo. Material sempre disponível, passível de ser (re)visitado, (re)significado, com a inscrição de texto e ou imagem em qualquer lugar da construção da narrativa. Este suporte contempla registos individuais ou do coletivo, em tempos simultâneos ou diferenciais, narrativas resultantes de conhecimento de vários olhares que se cruzam, assumindo uma implicação como campo de investigação, introduzindo uma plasticidade da escrita, com diferentes leituras, ampliando a dimensão da leitura na sua zona fronteiriça, onde se assume o risco da transformação de sentido.

Estas opções são particularmente relevantes neste grupo, uma vez que nele nos propomos aprofundar estes processos e temos elementos do Doutoramento em Educação Artística que estão a investigar sobre pesquisa baseada em artes (arts 
based research), especificamente a artografia (pensamento visual iniciado nos anos 80 na Faculdade de Educação da University of British Columbia UBC), pelo que a ligação a estas metodologias surge naturalmente:

Ao colocar a criatividade à frente do processo de ensino, pesquisa e aprendizagem, a a/r/tografia gera inovadores e inesperados insights, incentivando novas maneiras de se pensar, abordar e interpretar questões teóricas como um pesquisador, e práticas como um artista e educador. A questão crucial da a/r/tografia é: como nós desenvolvemos interrelações entre nosso fazer artístico e nossa compreensão e produção de conhecimento na academia como pesquisadores educadores? (Dias, 2009, p. 3177).

O registo durante as sessões por cartões cardográficos foi realizado individualmente por Ana Serra Rocha, num total de 18 sessões (sendo que não esteve presente em outras 6), tendo sido realizadas 4 sessões com cardografias coletivas em formato digital na plataforma canvas (imagem 5) ou padlet. A partir daí, os registos iniciaram-se colaborativamente com narrativas escritas e visuais, inspiradas por uma perspetiva artográfica, implicando a utilização de uma proposta visual realizada simultaneamente (ou não), que proporcionou que cada membro do grupo pudesse entrar e participar numa composição digital, completando, alterando, apagando e re-intrepretando; o que permitiu um sentimento de empatia, respeito e confiança. A permissão à alteração, à modificação, à re-leitura(s) estabeleceu um espaço de comunicação autêntica, que está disponível para o risco, a provocação, a reflexão e a criatividade, abrindo a possibilidade para o desenvolvimento de um resultado colaborativo.

Imagem 5 - GEPPAIE, Canvas colectivo, imagem 4 de 12 de acordo com o tema desolamento social realizado na sessão de 16/4/2021.

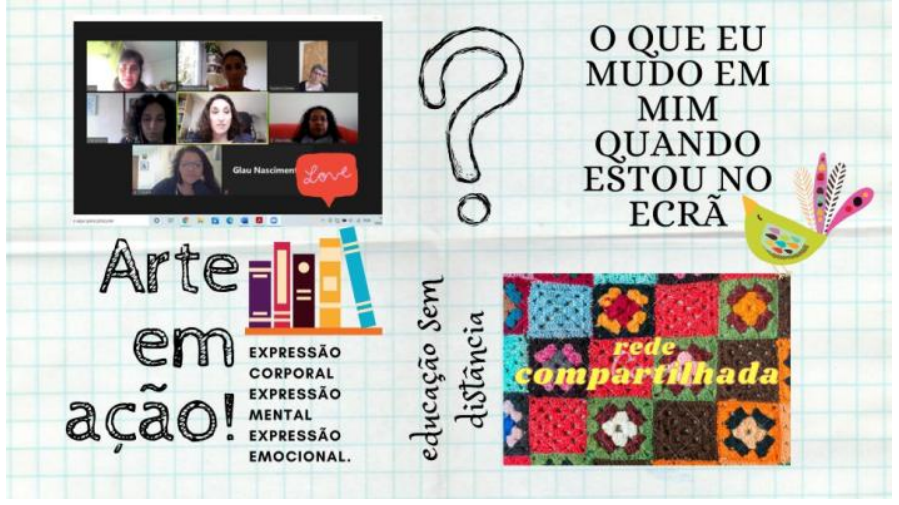

Fonte: GEPPAIE 2021. 
Esta abordagem tem sido reconhecida pelos membros como relevante para dinamizar a abordagem qualitativa, agitando, provocando e desafiando noções estanques e conservadoras, possibilitando a criação de novos lugares de estar, de refletir e de, neste entrelaçamento, aprender.

Optamos por apresentar agora uma sequência de excertos de uma escrita coletiva em construção, que tinha como mote a reflexão sobre como a pandemia nos afeta (imagem 6 - Quarentena em 100 actos - Mea Culpa/Culpa Minha), mas que desde o início apela à nossa liberdade criativa, aberta à possibilidade de cada um transformar o texto iniciado por outro. Foi um espaço de escrita do qual nos fomos apropriando como nosso, um lugar de relação afetiva e de intimidade, que diversas vezes questionamos poder tornarse uma peça de investigação participativa sobre as experiências de um coletivo universitário em tempos de confinamento pandêmico. Uma peça que é, por outro lado, confluência de diversos tipos de escrita e texto visual, onde se cruzam narrativas reflexivas de teor mais ou menos ficcional, textos poéticos e dramatúrgicos, aforismos e comentários sarcásticos, fotos, desenhos, fanzines, o que nos tem feito sonhar poder tornar-se livro, um dia, a publicar como uma produção 'fora da caixa' da autoria de uma comunidade que se pretende de aprendizagem e de pesquisa.

As escritas coletivas em construção são utilizadas como um método criativo em pesquisa, onde as interpretações e as escolhas de excertos aqui partilhados revelam visões e posicionamentos sobre os processos da escrita.

Imagem 6 - Excertos da escrita colectiva Quarentena em 100 actos - Mea Culpa/Culpa Minha (recolha em 30/5/2021).

Saltámos o 23! XXVII (ou XXIII)

É importante?

23 veio antes de tudo, porque 23 é importante mas já ficou lá atrás.

Quem está nos 23 é sempre maior ou igual de 23, como num capítulo que é melhor passar mais depressa. Ah fosse a vida uma sucessão de capítulos em que também pudéssemos mudar a numeração e eclipsar algumas partes, passar outras para as repetir:

\section{XXVIII}

Meio palmo de cara

Tem-se demonstrado que a maioria da população portuguesa, quando instada a usar máscara em locais públicos, nomeadamente em transportes, tem acedido com grande responsabilidade.

"Now that they died all, I don't know where to keep all my questions." Ava Gardner \& Ana Rocha 

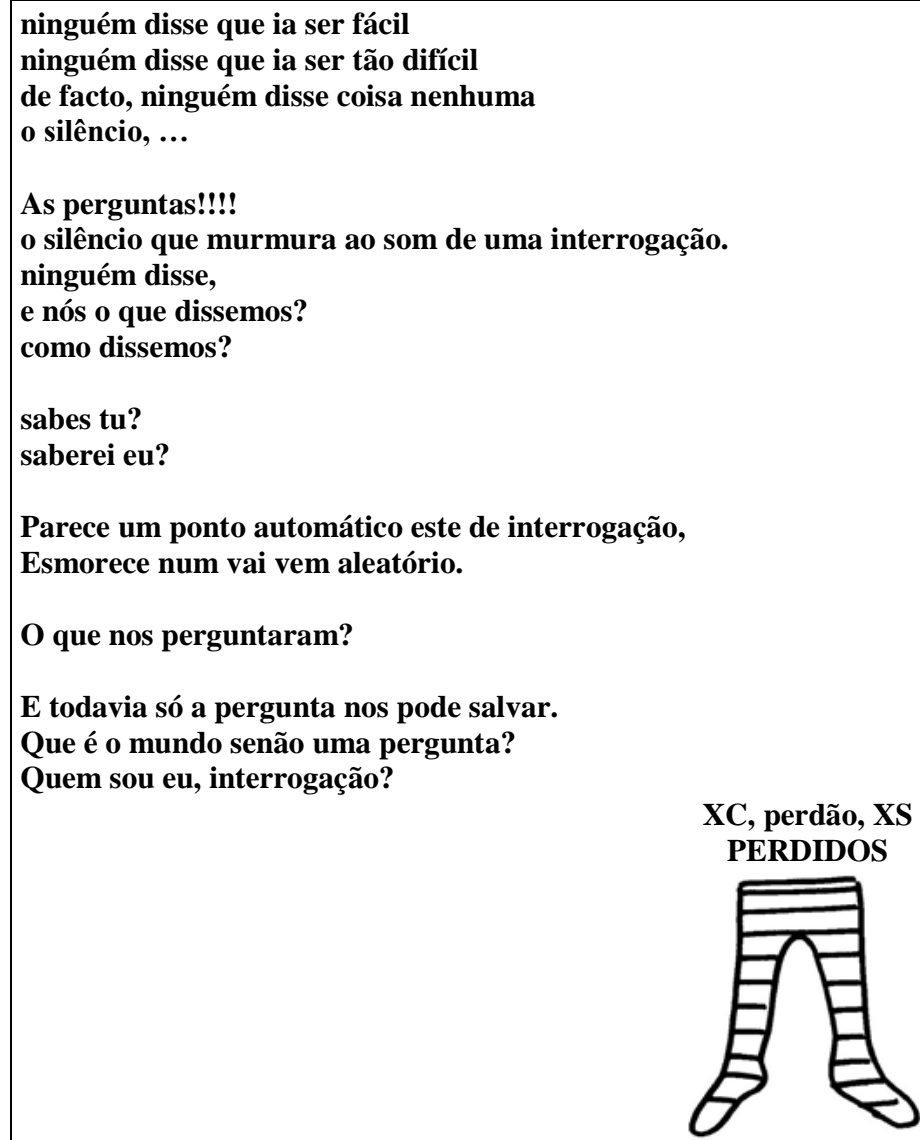

Collants são um bem essencial!

É inverno.

Faz frio.

A ameaça mundial ainda assombra as nossas vidas.

A venda de livros ao postigo não é permitida.

Nesta sequência vemos o aflorar de emoções vividas durante a pandemia (medo, cansaço, tédio, frustração, ansiedade, entre outras) e seus antídotos. Vemos a própria escrita a ser comentada, reflexivamente e/ou ironicamente. Lemos escritas sem texto que falam por si, anotamos a inclusão de textos de autores que nos são queridos, refletindo sobre a relação entre texto e corpo que resiste às máscaras. Vemos, ainda, reflexões poéticas sobre a importância das perguntas, a ecoar na relação, a mover-nos para a ação, a ancorar a nossa realidade e identidade. O propósito da integração desta sequência neste artigo poderá ser obscuro, sobretudo quando atentamos à sua inclusão numa tese de doutoramento. Urge então explicar um pouco a nossa intenção, pois o que pretendemos é ampliar possibilidades de construção de um conhecimento transdisciplinar (D’Ambrósio, 2017; Nicolescu, 1999; Petraglia, 2015) e multireferencial (Ardoino, 1999). O que queremos é ensaiar caminhos marcados pela heterogeneidade. O reconhecimento 
de que ciência e arte se podem integrar, faces de uma mesma realidade compósita, através de processos híbridos numa construção multivocal, inspirados em saberes que dialogam, provenientes de fontes múltiplas e diferentes ecologias, organizados numa ecologia própria (Morin, 2005; Santos, 2010, 2019).

\section{$O$ (des)encontro final}

Qual o lugar de processos colaborativos na construção de um livro-tese doutoral em educação artística? Qual a tese dentro da tese e que é espinha dorsal, agregando todas as peças, todas as produçõespáginas que farão parte desse livro?

Para a elaboração deste artigo solicitámos contributos ao grupo, enviámos previamente o primeiro esboço do texto, criou-se um padlet com os tópicos e questões inicialmente definidas e agendamos uma sessão para pensarmos juntos, com base nas perguntas que colocamos às experiências concretas que vamos vivendo, com o intuito de que a construção do conhecimento fosse realizada de forma dialógica.

Para finalizar e ainda sem fechar o texto, sublinhamos que temos vindo a perceber que falar acerca da escrita, passar da leitura ao diálogo e deste à escrita, numa plasticidade significante e de construção objetual, tem sido um processo que favorece o progresso dos projetos individuais e é suporte de uma teia rizomática em investigação, como nos relata uma das participantes. Deste modo, o coletivo e o individual cruzam-se para o aprofundamento da reflexão epistemológica, metodológica, ética e política, sendo também esse um propósito da tese de doutoramento de Ana Rocha.

A tese que se vai construindo, para a qual este artigo concorre, é esta:

O conhecimento construído nas teses doutorais na área da educação artística será/poderá ser um conhecimento híbrido e heterogéneo, que problematiza a própria área, nem arte nem ciência, arte mais do que ciência, ciência mais do que arte (Baldacchino, 2015), produção individual e coletiva, não só individual nem só coletiva, embora as fronteiras entre o individual e o coletivo se diluam, cada um de nós coletivo e cada coletivo integrando em si múltiplas individualidades. Nesta configuração, o GEPPAIE surge como um espaço privilegiado para o desenvolvimento destes processos.

No percurso do curso de Doutoramento em Educação Artística, a reflexão sobre o lugar do investigador foi considerada como um elemento charneira, no sentido em que a busca desse lugar, a sua conquista e habitabilidade levou à realização de um tempo de pesquisa através de diversos workshops de 
investigação, gerando a partilha, o diálogo, a escuta e subsequentemente, a escrita e criação de objetos de investigação, permitindo uma composição sobre estes lugares de aprendizagem. Considerando que a tese tem o seu lugar como um espaço habitável de experiências, reflexões, diálogos de aprendizagens, centrados na investigação crítica, e que nela se reflete precisamente sobre estas questões.

Na tese de Ana Serra Rocha, os workshops e encontros de investigação em construção e análise, que não acontecem só no contexto do GEPPAIE, têm-se desenvolvido com diferentes formatos, destacando-se a apresentação em congressos e seminários. O público passivo deu lugar a um envolvimento da audiência, em diferentes grupos heterogéneos, multiculturais e geracionais, onde "os participantes foram convidados a serem descobridores e investigadores, questionando-se de que forma o processo de construção, criação e manuseio do livro, poderá contribuir para uma cartografia de investigação" (Rocha, 2019, p. 161).

Todo este processo despoletou a escrita e manufatura de objetos tangíveis que estiveram na génese da preparação dos encontros seguintes, com o objetivo de investigar sobre o lugar da experiência do livro na mediação educativa e na reflexão epistemológica. Foi então imprescindível a partilha e produção visual, como forma de pesquisa baseada em artes. Desde então, a proposta de tese de doutoramento assumiu uma componente prática de investigação (workshops de investigação), a par da decisão de realizar uma tese por artigos, que resultam na construção de um objeto livro - tese de doutoramento (que eventualmente poderá ser catalogado como livro de artista). Neste encadeamento, entre os workshops de investigação, entre os registos e produções escritas e gráficas, e entre a realização de artigos, a imagem visual constitui-se como elemento crucial acompanhando o processo investigativo, num questionamento epistemológico e procura de construção do conhecimento. Os processos entrelaçam-se entre a escrita, a leitura e a grafia e é deste enlace que se materializa o conhecimento em formalivro. A procura do lugar da experiência do livro em contextos de diversidade académica tem sido uma constante e verifica-se que, neste espaço, se tem vindo a construir uma relação emancipatória com os processos de conhecimento.

Realçamos, neste âmbito, a importância da visualização do processo de pesquisa e do pensamento, através de diversas técnicas, para explorar projetos de investigação e/ou para apresentar os seus resultados. Esta metodologia é baseada num contexto de arts based research, 
fazendo uso do conceito de pesquisa como elemento experiencial de partilha e de feedback, gerando novas ideias. No caso da doutoranda Ana Serra Rocha estes elementos são maioritariamente livros e apresentações artísticas no sentido de poder também encorajar respostas inovadoras e originais (Gray \& Malins, 2017).

O livro como objeto e resultado de investigação é um processo que ajuda a refletir e a contextualizar a investigação em curso, encoraja a colaboração interdisciplinar, e desenvolve-se como um repositório de informação e recolha que pode ser exposto e consultado sempre que necessário, estendendo o seu entendimento e leitura para além da sua forma/situação inicial. O objecto livro de investigação pode ser realizado em diferentes suportes (imagem 7), construído a partir das evidências como um portefólio da aprendizagem. Pretende capturar e transmitir o processo da dinâmica realizada, de forma a partilhar o retorno da investigação. Estas propostas multimétodos, multi-participativas em grupos heterogéneos possibilitam diferentes tipos de informação e de experiências, que em rede estabelecem uma teia orgânica e versátil de conhecimento, em combinações relacionais diversas, que trazem novas possibilidades e evidências.

Trata-se de uma tese para ser defendida, comprovada, mas, sobretudo criada, pelo livro - tese - que a concretiza, "pois só pode haver investigação participativa numa comunidade que partilhe os mesmos princípios democráticos" (Paz, 2020, p. 2).

Imagem 7 - A Pergunta. Caixa das perguntas desenvolvida no âmbito da apresentação Playing Scenes no $8^{\circ}$ Encontro em práticas de investigação em educação artística (EPRAE) no Porto em 2021.

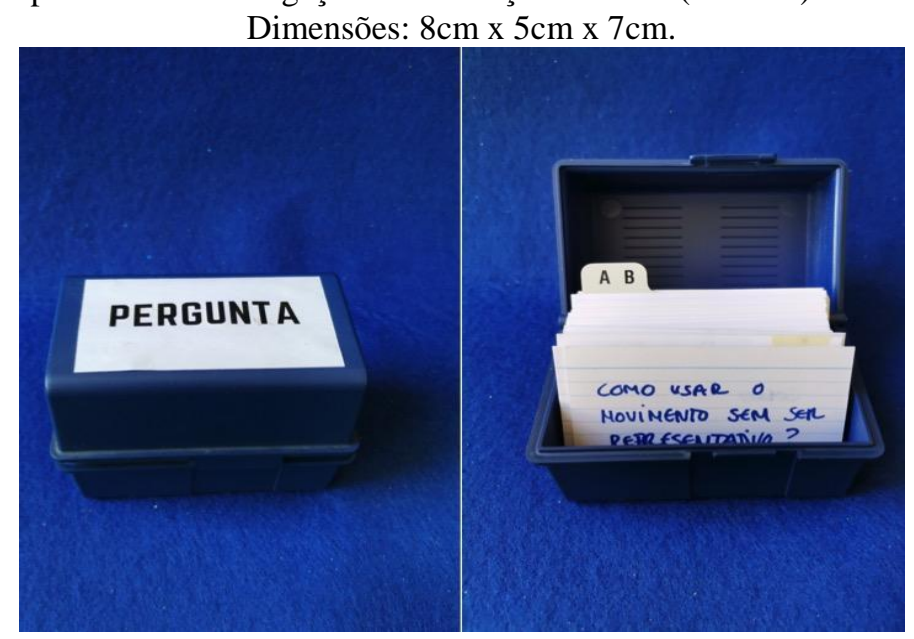

Fonte: Ana Serra Rocha 2021. 


\section{Agradecimentos}

Agradecimentos aos membros GEPPAIE e IE/ULisboa.

\section{Referências}

Atkinson, D. (2012). Contemporary art and art in education: the new, emancipation, and truth. International Journal of Art and Design Education, 31(1), 5-18. https://doi.org/10.1111/j.14768070.2012.01724.x

Atkinson, D. (2015). The adventure of pedagogy, learning and the not-known. Subjectivity, $\quad 8(1), \quad 43-56$. https://doi.org/10.1057/sub.2014.22

Atkinson, D. (2018). Art, disobedience and ethics: The adventure of pedagogy. Londres: Pallgrave Macmillan. https://doi.org/10.1007/978-3-319-62639-0

Augusto, A. I. (2020). Estória(s) do(s) meu(s) tempo(s) e espaço(s) em branco. Documento não publicado.

Ardoino, J. (1999). La complexité. In E. Morin (Ed.), Relier les connaissances (pp. 442-449). Paris: Seuil.

Baldacchino, J. (2015). Art \pm Education: The paradox of the ventriloquist's soliloquy. Sysiphus, 3(1), 62-79. Recuperado de: http://revistas.rcaap.pt/sisyphus/article/vie w/7719

Baran, P. (1964). On distributed communications. 1 Introduction to distributed communications network. https://doi.org/10.7249/RM3420

Boavida, A. M., \& Ponte, J. P (2002). Investigação colaborativa: Potencialidades e problemas. In GTI (Org), Reflectir $e$ investigar sobre a prática profissional (pp. 43-55). Lisboa: APM.

Caetano, A. P., Paz, A. L., Narduela, A., Pardal, A., Rocha, A. S., Ré, S., Silva Correia, C., Marques, C., Silva, H.R., Andrade, Carvalho, M.M. \& Meireles, T. (2019a). As artes no ensino superior 'Pedagogias do evento' no doutoramento em educação artística. In S. Gonçalves \& J. J. Costa (Eds.), Diversidade no ensino superior (pp. 239-260). Coimbra: CINEPIPCe.

Caetano, A. P., Paz, A. L., Freire, I., \& Carvalho, C. (2019b). Processos participativos e artísticos em contextos de diversidade. Lisboa: Colibri.

Caetano, A. P., Paz, A. L., Rocha, A. I., \& Marques, C. (2020a). Narrativas de investigação e formação em educação artística, no ensino superior - escrita dialógica em devir. Revista Educação, Artes e Inclusão, 16(1), 8-33. https://doi.org/10.5965/198431781601202 $\underline{0008}$

Caetano, A. P., Freire, I. P., \& Machado, E. B. (2020b). Student voice and participation in intercultural education. Journal of New Approaches in Educational Research, $9(1), \quad$ 57-73. https://doi.org/10.7821/naer.2020.1.458

D'Ambrósio, U. (2017). Transdisciplinaridade, ética e futuro. In E. Guérios et al. (Org.). Complexidade $e$ educação: Diálogos epistemológicos transformadores (pp. 26-40). Curitiba: CRV.

https://doi.org/10.24824/978854441765.2

Deleuze, G., \& Guattari, F. (2002). A Thousand Plateaus: Capitalism and Schizophrenia. Londres/Nova Iorque: Continuum. 
Dias, B. (2009). Uma epistemologia de fronteiras: minha tese de doutorado como um projeto a/r//tográfico. http://www.anpap.org.br/anais/2009/pdf/ce av/belidson_dias_bezerra_junior.pdf

Flecha, R. (Ed.). (2015). Successful educational actions for inclusion and social cohesion in Europe. Springer. https://doi.org/10.1007/978-3-319-11176-6

Freire, P. (1975). Pedagogia do Oprimido. Porto: Afrontamento.

Freire, P. (1977). A mensagem de Paulo Freire. Teoria e prática da libertação. Porto: Nova Crítica.

Gray, C., \& Malins, J. (2017) Visualizing Research: a guide to the research process in art and design. Routledge. https://doi.org/10.4324/9781315547923

Loss, A. S. (2019). Formação de professores: processos autoformativos... Quem cuida do(a) professor(a). In A.P. Caetano et al. (orgs.), Processos participativos e artísticos em contextos de diversidade (pp. 96-84). Lisboa: Colibri.

Machado, E., Freire, I, Caetano, A. P., Vassalo, S., \& Bicho, L. (2020). The voice of young people - contribution for their involvement in the school. Intercultural Education, 31(3), 1-14. https://doi.org/10.1080/14675986.2020.17 $\underline{17291}$

Maisonneuve, J. (2004). A dinâmica dos grupos. Lisboa: Livros do Brasil

Moran, J. (2015). Educação híbrida: um conceito-chave para a educação, hoje. In L. Bacich, A.T. Neto \& F.M. Trevisani (Orgs.), Ensino híbrido: personalização $e$ tecnologia na educação (pp. 27-45). Porto Alegre: Penso.
Morin, E. (2005). Amor, poesia $e$ sabedoria. Rio de Janeiro: Bertrand Brasil.

Nicolescu, B. (1999). Une nouvelle vision du monde - la transdiciplinarité. In D’Ambrosio, U., et al. (Eds.). Transdisciplinarity/Transdisciplinarité (pp. 157-161). Lisboa: Hugin.

Ornelas, J. (2008). Psicologia Comunitária. Lisboa: Fim de Século.

Paz, A. L. (2020). 4. Que democracia? In GEPPAIE. $O$ que é investigação participativa? Em que se diferencia de outras abordagens? Que tensões e dilemas equacionamos nos nossos projetos? Documento não publicado.

Paz, A. L., \& Caetano, A. P. (2019). Uma pedagogia do evento no doutoramento em educação artística. In A.P. Caetano et al. (Eds.), Processos participativos $e$ artísticos em contextos de diversidade (pp. 19-36). Lisboa: Colibri.

Paz, A. L., \& Caetano, A. P. (2020). Arts education and writing as research and pedagogic practice: Critical perspectives in higher education or how we became the teachers yet to come. Art, Design \& Communication in Higher Education, 19(2), 185-201. https://doi.org/10.1386/adch_00022_1

Petraglia, I. (2015). O processo de produção do conhecimento: complexidade e transdisciplinaridade. In Behrens, M. A. \& Ens, R. T. (Eds.). Complexidade $e$ transdisciplinaridade. Novas perspetivas teóricas e práticas para a formação de professores (pp. 75-86). Curitiba: Appris.

Pina, C. I., \& Caetano, A. P. (2019). Participação jovem e educação intercultural numa escola profissional. In , A.P. Caetano et al. (Eds.). Processos participativos e artísticos em contextos de diversidade (pp. 85-117). Lisboa: Colibri. 
Rocha, A. (2019). Processos participativos e artísticos em contextos de diversidade. In A. P. Caetano et al. (Orgs.). O lugar da experiência do livro na mediação educativa e na reflexão epistemológica (pp. 161-171). Lisboa: Colibri.

Santos, B. S. (2010). Descolonizar el saber, reinventar el poder. Montevideu: Ediciones Trilce.

Santos, B. S. (2019). Educación para otro mundo posible. Buenos Aires: Clacso/Medellin CEDALC. https://doi.org/10.2307/j.ctvnp0k2z

Teixeira, A. R., \& Rocha, A. S. (2021). Playing back meanings through bodies and books. EPRAE - $8^{\circ}$ Encontro em Práticas de Investigação em Educação Artística, Porto: Faculdade de Belas Artes da Universidade do Porto. i2ADS, No prelo.

Informações do Artigo / Article Information

Recebido em : 15/06/2021

Aprovado em: 25/08/2021

Publicado em: 30/09/2021

Received on June 15th, 2021

Accepted on August 25th, 2021

Published on September, 30th, 2021

Contribuições no Artigo: As autoras foram as responsáveis por todas as etapas e resultados da pesquisa, a saber: elaboração, análise e interpretação dos dados; escrita e revisão do conteúdo do manuscrito e; aprovação da versão final publicada.

Author Contributions: The author were responsible for the designing, delineating, analyzing and interpreting the data, production of the manuscript, critical revision of the content and approval of the final version published.

Conflitos de Interesse: As autoras declararam não haver nenhum conflito de interesse referente a este artigo.

Conflict of Interest: None reported.

Avaliação do artigo

Artigo avaliado por pares.

Article Peer Review

Double review.

\section{Agência de Fomento}

Este artigo foi financiado pela FCT - Fundação para a Ciência e Tecnologia, IP, no âmbito da UIDEF - Unidade de Investigação e Desenvolvimento em Educação e Formação - UIDB/04107/2020

\section{Funding}

This article was funded by FCT - Fundação para a Ciência e Tecnologia, IP, under the UIDEF - Unidade de Investigação e Desenvolvimento em Educação e Formação - UIDB/04107/2020.

Como citar este artigo / How to cite this article

APA

Rocha, A. S., Caetano, A. P., \& Paz, A. L. (2021). Narrativas entrelaçadas no ensino superior - Como nos constituímos enquanto comunidade e produzimos colaborativamente conhecimento emancipatório sobre investigação baseada em artes?. Rev. Bras. Educ. Camp., 6, e12458. http://dx.doi.org/10.20873/uft.rbec.e12458

ABNT

ROCHA, A. S.; CAETANO, A. P.; PAZ, A. L. Narrativas entrelaçadas no ensino superior - Como nos constituímos enquanto comunidade e produzimos colaborativamente conhecimento emancipatório sobre investigação baseada em artes?. Rev. Bras. Educ. Camp., Tocantinópolis, v. 6, e12458, 2021. http://dx.doi.org/10.20873/uft.rbec.e12458 